March 21, 2011

\title{
Fukushima Nuclear Power Plant Accident
}

The International Commission on Radiological Protection (ICRP) does not normally comment on events in individual countries. However, we wish to express our deepest sympathy to those in Japan affected by the recent tragic events there. Our thoughts are with them.

Throughout we have kept and continue to keep abreast of events as they unfold, particularly those at the Fukushima Nuclear Power plant, through some of our Japanese colleagues and information being provided by national and international organisations and professional societies.

We hope that the current effort to regain control of the situation will soon be successful and that our recent recommendations on radiological protection in emergency situations and for contaminated territories have and will prove helpful in dealing with the present and future circumstances.

The Commission continues to recommend optimisation and the use of reference levels to ensure an adequate degree of protection with respect to exposure to ionising radiation in emergency and existing exposure situations.

For the protection of the public during emergencies the Commission continues to recommend that national authorities set reference levels for the highest planned residual dose in the band of 20 to 100 millisieverts (mSv) (ICRP 2007, Table 8).

When the radiation source is under control contaminated areas may remain. Authorities will often implement all necessary protective measures to allow people to continue to live there rather than abandoning these areas. In this case the Commission continues to recommend choosing reference levels in the band of 1 to $20 \mathrm{mSv}$ per year, with the long-term goal of reducing reference levels to $1 \mathrm{mSv}$ per year (ICRP 2009b, paragraphs 48-50).

The Commission continues to recommend reference levels of 500 to $1000 \mathrm{mSv}$ to avoid the occurrence of severe deterministic injuries for rescue workers involved in an emergency exposure situation. This means that it will be justified to expend 
significant resources, both at the planning stage and during the response, if required, in order to reduce expected exposures to below these levels (ICRP 2007, Table 8 and ICRP 2009a, paragraph e).

Furthermore, the Commission continues to recommend no dose restrictions for lifesaving efforts by informed volunteers if the benefit to others outweighs rescuer's risk (ICRP 2007, Table 8).

We are closely following the tremendous efforts of the professionals in Japan dealing with this difficult situation and, during our upcoming meeting in Seoul, are planning to review lessons learned in relation to our recommendations on emergency exposure situations.

On behalf of the International Commission on Radiological Protection,

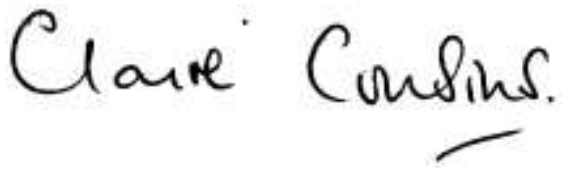

Claire Cousins

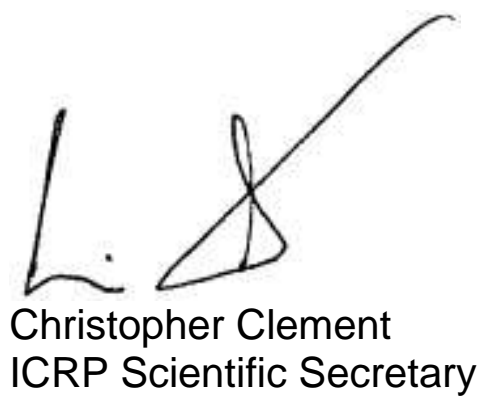

\section{References}

ICRP, 2007. The 2007 Recommendations of the International Commission on Radiological Protection. ICRP Publication 103, Ann ICRP 37 (2-4).

ICRP, 2009a. Application of the Commission's Recommendations for the Protection of People in Emergency Exposure Situations. ICRP Publication 109, Ann ICRP 39 (1).

ICRP, 2009b. Application of the Commission's Recommendations to the Protection of People Living in Long-term Contaminated Areas after a Nuclear Accident or a Radiation Emergency. ICRP Publication 111, Ann ICRP 39 (3). 